\title{
Clarissa Hameister erhält Förderpreis
}

\section{Mitgliederversammlung des Arbeitskreises Mammasonografie}

Der diesjährige Förderpreis des Arbeitskreises Mammasonografie geht an Clarissa Hameister aus dem Institut für Röntgendiagnostik am Helios-Klinikum Berlin-Buch. Im Rahmen der Mitgliederversammlung des Arbeitskreises wurde die junge Ärztin mit dem Förderpreis für ihr Promotionsthema über die „Korrelation der Pathophysiologie des Mammakarzinom-Randes mit modernen sonografischen Techniken“ ausgezeichnet. In ihrer Arbeit wurden sonografisch detektierte Mammakarzinome sowohl im B-Bild als auch mithilfe eines farbcodierten Ultraschallprogramms ASQ (accustic structure quantification) untersucht. Hierbei haben sich visuelle Parallelen zwischen der peritumoralen Zone im ASQ-Modus und dem klassischen Halo in der B-Bild-Sonografie ergeben. Diese Phänomene wurden hinsichtlich möglicher histopathologischer Korrelationen untersucht und ihre Wertigkeit in der Diagnostik maligner Brustläsionen durch ungeübte Untersucher erprobt. Die Arbeit wurde unterstützt durch ihren Mentor Professor Dr. med. Thomas Fischer, Interdisziplinäres Ultraschallzentrum des Instituts für Radiologie, Campus Charité Mitte.

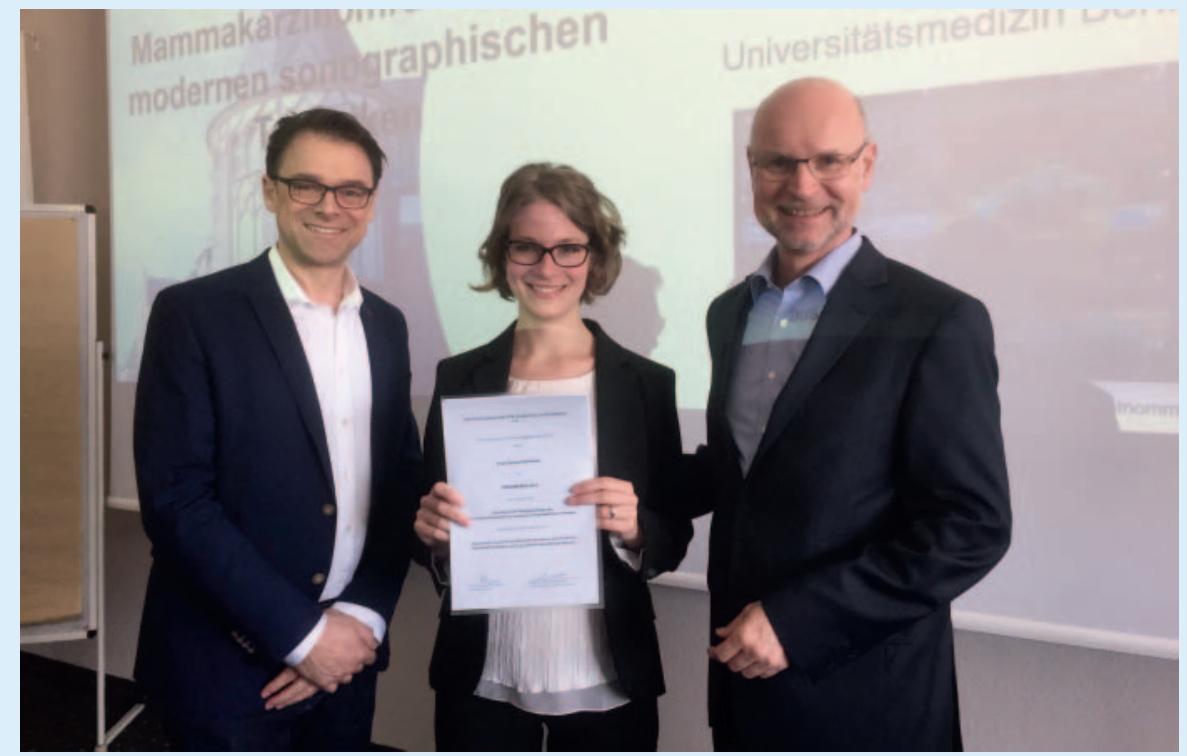

(Von links nach rechts): Stellvertretender Sprecher des Arbeitskreises Mammasonografie, Prof. Dr. Markus Hahn, Förderpreisgewinnerin Clarissa Hameister und Sprecher des Arbeitskreises, Prof. Dr. Werner Bader. Quelle: Prof. Werner Bader, Bielefeld

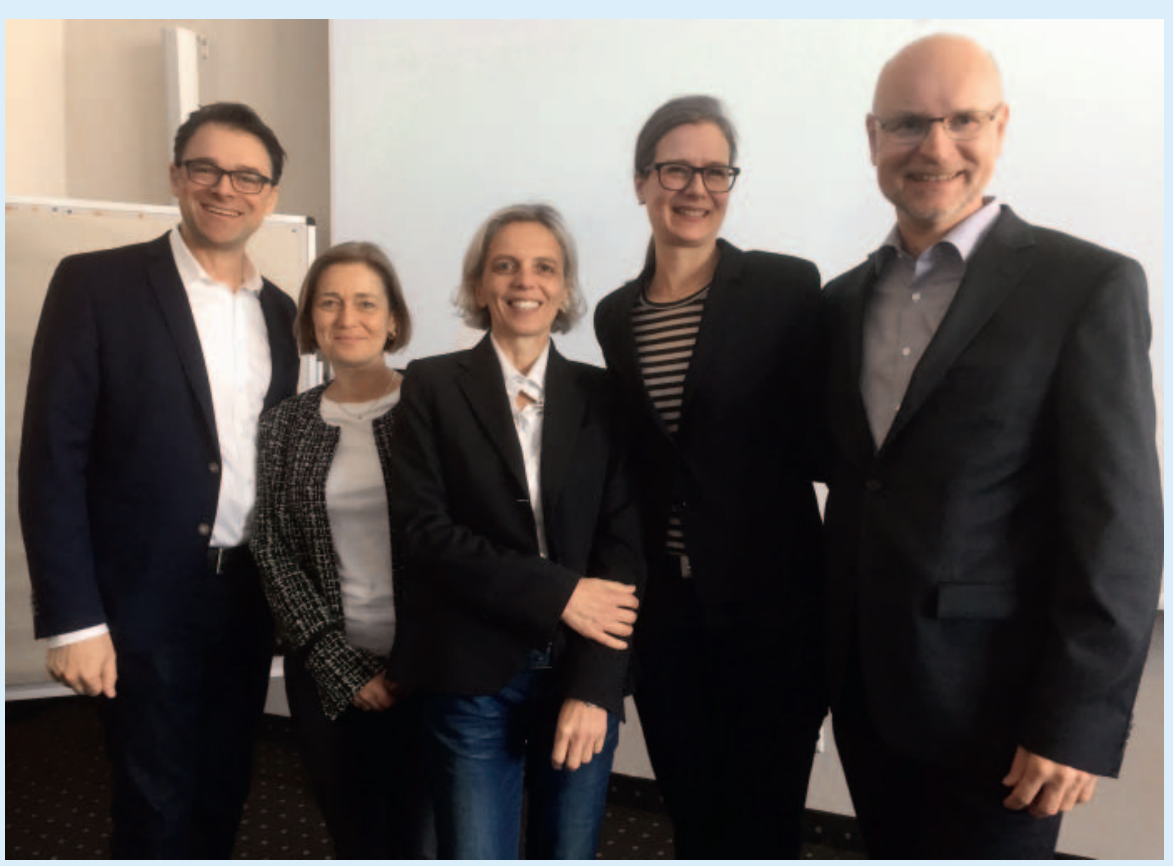

Der Arbeitskreis Mammasonographie freut sich über die Ernennungen zur Stufe III von Professor Dr. med. Christine Solbach (Mitte) und PD Dr. med. Ines Verena Gruber (zweite von rechts) sowie über die Ernennung zur DEGUM II-Kursleiterin Dr. medic Claudia Vogel-Minea (zweite von links). Alle Kolleginnen überzeugten mit einem hervorragenden Vortrag und einer hohen wissenschaftlichen Expertise im Rahmen der Mitgliederversammlung des Arbeitskreises am 25. Mai 2019 in Frankfurt. Quelle: Prof. Werner Bader, Bielefeld 